\title{
Does outward appearance appeal to the inward mind? The impact of packaging finishes on brand impressions and the subsequent behavior of consumer
}

\author{
Citation for published version (APA): \\ Chen, Y-S. (2021). Does outward appearance appeal to the inward mind? The impact of packaging finishes on \\ brand impressions and the subsequent behavior of consumer. Journal of Product \& Brand Management, 30(5), \\ 768-778. https://doi.org/10.1108/jpbm-07-2019-2466
}

DOI:

10.1108/jpbm-07-2019-2466

Document status and date:

Published: 21/05/2021

\section{Document Version:}

Publisher's PDF, also known as Version of Record (includes final page, issue and volume numbers)

\section{Please check the document version of this publication:}

- A submitted manuscript is the version of the article upon submission and before peer-review. There can be important differences between the submitted version and the official published version of record. People interested in the research are advised to contact the author for the final version of the publication, or visit the $\mathrm{DOI}$ to the publisher's website.

- The final author version and the galley proof are versions of the publication after peer review.

- The final published version features the final layout of the paper including the volume, issue and page numbers.

Link to publication

\footnotetext{
General rights

- You may freely distribute the URL identifying the publication in the public portal. follow below link for the End User Agreement:

www.tue.nl/taverne

\section{Take down policy}

If you believe that this document breaches copyright please contact us at:

openaccess@tue.nl

providing details and we will investigate your claim.
}

Copyright and moral rights for the publications made accessible in the public portal are retained by the authors and/or other copyright owners and it is a condition of accessing publications that users recognise and abide by the legal requirements associated with these rights.

- Users may download and print one copy of any publication from the public portal for the purpose of private study or research.

- You may not further distribute the material or use it for any profit-making activity or commercial gain

If the publication is distributed under the terms of Article $25 \mathrm{fa}$ of the Dutch Copyright Act, indicated by the "Taverne" license above, please 


\title{
Does outward appearance appeal to the inward mind? The impact of packaging finishes on brand impressions and the subsequent behavior of consumer
}

\author{
Yu-Shan Athena Chen \\ Department of Industrial Design, Eindhoven University of Technology, Eindhoven, The Netherlands
}

\begin{abstract}
Purpose - The purpose of this study is to identify conditions under which consumers prefer matte packages and those under which they prefer glossy packages and to extend the findings to the context of consumer evaluations.

Design/methodology/approach - A series of four experiments-conducted across a diverse range of settings and consumers (through lab experiments and field studies) and using different types of products (mobile phones, invitation cards, wrappers and coffee packs)- examined the effects of matte and glossy packaging finishes on consumer evaluations (i.e. preferences, attitudes and purchase intentions). This paper further developed moderated mediation models to illustrate the mechanisms underlying the examined effects.

Findings - People with warmth and competence focus favored matte and glossy packaging, respectively. In addition, the warmth (competence) focus enhanced the positive influence of matte (glossy) packaging on brand sincerity (competence), leading to more favorable consumer evaluations (i.e. brand attitudes, product attitudes and purchase intentions).

Practical implications - This study provides managers with insights into conferring desired impressions of sincerity (competence) upon a brand and methods of attracting certain warmth focused (competence focused) consumers by using matte (glossy) packaging finishes.

Originality/value - This is the study to systematically investigate the effect of packaging finishes on brand impressions and consumer evaluations.
\end{abstract}

Keywords Brand competence, Brand sincerity, Competence focus, Glossy packaging, Matte packaging, Warmth focus

Paper type Research paper

\section{Introduction}

Packaging is a critical aspect of marketing because it constitutes a powerful means of enhancing certain product attributes and brand impressions through its graphical, textual and structural design elements (Celhay and Trinquecoste, 2015; Cornil et al., 2017; Deng and Srinivasan, 2013; Fenko et al., 2016; Magnier and Schoormans, 2017; Ye et al., 2019). Among these elements, packaging finishes have recently attracted the attention of researchers, who have mostly focused on their role in enhancing product attributes. For example, Magnier et al. (2016) observed that sustainable packaging led to a perception of high food quality. However, to date, knowledge about the brand impressions stimulated by certain packaging finishes, the psychological mechanism that may be involved and the factors that may drive consumer evaluations remain limited.

In the current study, we hypothesized that matte packaging leads to impressions of sincerity and, in turn,

The current issue and full text archive of this journal is available on Emerald Insight at: https://www.emerald.com/insight/1061-0421.htm

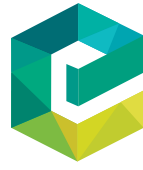

Journal of Product \& Brand Management 30/5 (2021) 768-778

Emerald Publishing Limited [ISSN 1061-0421] [DOI 10.1108/JPBM-07-2019-2466] attracts target consumers who rely on warmth related information in forming their attitudes. By contrast, glossy packaging leads to impressions of competence and, in turn, attracts consumers who focus on competence related information in developing their attitudes. Because of these effects, favorable attitudes could hinge on the linkage between matte packaging and consumers' warmth and between glossy packaging and a focus on competence. These hypotheses were examined in a series of four experiments.

(C) Yu-Shan Athena Chen. Published by Emerald Publishing Limited. This article is published under the Creative Commons Attribution (CC BY 4.0) licence. Anyone may reproduce, distribute, translate and create derivative works of this article (for both commercial and non-commercial purposes), subject to full attribution to the original publication and authors. The full terms of this licence may be seen at http://creativecommons.org/licences/ by/4.0/legalcode

The author sincerely appreciates Wei-Ken Hung (National United University, Taiwan) for crafting the materials and assisting with data collection. The author sincerely appreciates SINBON Electronics Co., Ltd. for assisting with data collection.

Received 17 July 2019

Revised 13 December 2019

30 April 2020

7 July 2020

Accepted 15 July 2020 


\section{Theoretical background}

\section{Conveyance of matte and glossy packaging}

Research efforts have been increased over the past decade to unpack the extensive effects of packaging on consumers' perceptions of the corresponding products (Magnier and Schoormans, 2017). The effects of matte and glossy packaging have primarily been investigated from the connotations that surface appearances evoke. Two appearances determine whether a surface is perceived as matte or glossy. One is how it is touched. Matte surfaces are rough and soft, whereas glossy surfaces are smooth and hard (Briand Decré and Cloonan, 2019; Kergoat et al., 2012; Tiest and Kappers, 2007). The other is how it reflects light. On matte surfaces, reflections of light are more diffuse and distributed in a wide range of directions; by contrast, a glossy or even mirror-like appearance has single-angle light reflections (Nayar and Oren, 1995). Then, the connotations of matte finish could be understood as the knowledge constructs associated with rough/soft touch and diffuse light reflections; whereas, the connotations of glossy finish could be realized as knowledge constructs associated with smooth/hard touch and single-angle light reflections.

For example, packaging roughness may lead customers to perceive a yogurt sample served in a matte pot as more granular than an identical yogurt sample served in a glossy pot (Piqueras-Fiszman and Spence, 2012). Similarly, because organic materials such as earth or clay produce diffuse reflections as matte packaging does, the foods in matte packaging are perceived to be more natural and organic than that in glossy packaging (Magnier et al., 2016). Natural and organic foods should be of high quality. Accordingly, matte packaging also links to high food quality (Marckhgott and Kamleitner, 2019). In a similar vein, we elaborate that matte surface may connote social warmth and the glossy surface may convey competence.

Matte and social warmth. A soft touch is closely linked to intimacy (i.e. social warmth). Harlow's study "the nature of love" involving macaque monkeys in 1958 highlighted the role of soft-touch in the mother-infant relationship (Harlow, 1958). In this experiment, a substitute mother composed of soft cloth provided comfort and warmth, whereas a mother composed of harsh wire provided nutrition. Infant macaque monkeys preferred to stay close to the soft-cloth mother over the harshwire surrogate mother. Furthermore, physiological evidence reveals that a soft and plush touch increases the "love hormone" (i.e. oxytocin) and reduces the "stress hormone" (i.e. cortisol), indicating the mechanisms through which a soft and plush touch promotes interpersonal intimacy (Sumioka et al., 2013; Tai et al., 2011).

Considering marketing practices, Peck and Wiggins (2006) investigated whether the addition of soft-touch elements to museum brochures influenced the purchase of new memberships. They found that museum visitors who were given the brochures with the soft-touch elements gave a more favorable review to the brochure and were more willing to purchase the membership than did visitors who were not given the brochure with the soft-touch elements. Peck and Wiggins drew a connection between the touch of the brochure and a favorable attitude and willingness to pay. However, an alternate and richer explanation could be that the soft touch of the matte surface provided a sense of social warmth that aligns with the core value of a children's museum where family warmth and joyfulness are the primary focus. Mother-infant relationship, love, interpersonal intimacy and family warmth are all involved in social warmth. Accordingly, we argue that matte may convey social warmth.

Glossiness and competence. As mentioned, on glossy surfaces, light is reflected from only a single angle (Nayar and Oren, 1995). Specifically, the glossiness is defined by three features of light reflection, namely, high brightness, sharpness and contrast. Brightness and sharpness project the target (Fleming et al., 2004; Marlow and Anderson, 2013). A compelling gloss perception can be crafted by highlighting the edges of brightness and darkness (contrast; Kim et al., 2012). Beyond surface features, viewing objects from a distance enhances the perception of glossiness because observers cannot resolve the finer scale of the texture of the material (Qi et al., 2012).

We propose that glossiness may convey competence. This connection is evident in metaphors such as "he shines at science," "she is as sharp as a tack" or "he offers by far and away from the best prospect" that is widely used to describe someone's competence in daily life across different cultures. Furthermore, although this conjecture has never been experimental examined, a similar idea is captured in packaging literature. Specifically, Fujisaki et al. (2015) posited that a glossiness connotes "expensiveness, sturdiness, rareness, interestingness and sophisticatedness" (p. 185). There is also evidence showing that glossy products are perceived as luxury, elegance and high quality because of the implied superior effort involved in making that product (Briand Decré and Cloonan, 2019; Silvia et al., 2018; Yanagisawa and Yuki, 2011). These connotations and product characteristics are consistent with the nature of competence.

\section{Brand sincerity and competence}

Brand personality. Aaker's (1997) brand sincerity and competence correspond to interpersonal impressions of social warmth and competence, respectively. The sincerity dimension is composed of homeliness, honesty, genuineness and cheerfulness impressions. The competence dimension is composed of reliability, responsibility, dependability and efficiency impressions. Brands perceived to possess such a skill set for competent execution are associated with intelligence, success and leadership.

Packaging finishes and brand impressions. Matte packaging is allied to the formation of sincere impressions. This conjecture is evident in Orth and Malkewitz (2008, p. 64) that "sincere brands should have natural package design" because of the strong relationship between impressions of sincerity and natural package design. Consistent with Orth and Malkewitz (2008), Magnier and Schoormans (2017) found that fiberbased packages (i.e. matte packages) communicate a brand's eco-friendliness and high social responsibility (i.e. sincerity). Accordingly, this study proposed the following hypothesis. 
H1a. Consumers perceive brands applying matte packaging as more sincere than brands applying glossy packaging.

Although the relationship between glossiness and brand competence remains unexplored, the knowledge accumulated so far shines a light on our conjuncture. Orth and Malkewitz (2008) indicated that high-contrast and delicate designs induced impressions of brand competence. High contrast is actually a criterion through which individuals define glossiness. Furthermore, the typical features of glossy objects, namely, high brightness, fineness and sleekness, are associated with a delicate design. The associations of delicate design with high quality, high elegance and high cost also lead to perceptions of brand competence. Accordingly, the study proposed the following hypothesis.

H1b. Consumers perceive brands applying glossy packaging as more competent than brands applying matte packaging.

\section{Individual difference in warmth and competence focus} Social warmth and competence dominate interpersonal impression formation. Social warmth comprises the items congeniality, kindness, friendliness, trustworthiness and helpfulness impressions, whereas competence comprises the items' confidence, ambition, effectiveness, intelligence, power and expertise impressions. Collectively, the two dimensions almost completely account for the manner through which people characterize others (stereotype content model; Fiske et al., 2002). Recently, warmth and competence dimensions have been applied to the study of brand and firm perceptions.

Match between the focus of consumers and information conveyed by packaging. Preference of an object depends on whether or not people value it. For example, Piqueras-Fiszman and Spence (2012) reported that matte and glossy containers indicate the crunchiness and smoothness of food, respectively. Favorable attitudes emerge when the conveyed information of crunchiness and smoothness matches what consumers value in cookies (i.e. crunchy) and yogurt (i.e. creamy), respectively. In a similar vein, Hess and Melnyk (2016) noted that pink and blue colors activate gender-related knowledge of warmth and competence (i.e. consumers' current focuses), which spills over to the brands. A brand can stimulate strong purchase intentions by promoting feminine products in pink packages but masculine products in blue packages.

Building on the aforementioned findings, we propose that if matte packaging conveys warmth, consumers who focus on social warmth (hereafter, warmth focused consumers) would prefer products contained in matte packages to those in glossy packages because of the match between the consumers' focus and the information conveyed by the packaging. Similarly, if glossy packaging conveys competence, consumers who focus on competence (hereafter, competence focused consumers) would prefer products contained in glossy packages to those in matte packages. Favorable attitudes and high purchase intentions also correspond to product preference. Accordingly, we proposed the following hypotheses:

H2a. Warmth focused consumers prefer products contained in matte packages over those contained in glossy packages. However, competence focused consumers prefer products contained in glossy packages over those contained in matte packages.

$H 2 b$. Warmth focused customers have more favorable attitudes toward products contained in matte packages than they do toward those contained in glossy packages. However, competence focused customers have more favorable attitudes toward products contained in glossy packages than they do toward those contained in matte packages.

H2c. Warmth focused customers are willing to pay more for products contained in matte packages than for those contained in glossy packages. However, competence focused customers are willing to pay more for products contained in glossy packages than for those contained in matte packages.

Match between consumers' focus and brand impressions. Again, the preference of an object depends on whether or not people value it. Although brand sincerity and competence are valuable impressions, consumers' focus on warmth and competence shifts the balance in terms of how people are concerned with each impression. As noted in $H 1 a$ and $H 1 b$, we expected that brands applying matte packaging are perceived to be sincere, whereas brands applying glossy packaging are perceived to be competent. Consequently, warmth focused consumers should have favorable attitudes toward brands applying matte packaging because of the induced sincere impressions. Similarly, competent-focused consumers would have favorable attitudes toward brands applying glossy packaging because of evoked competence impressions. Hence, we proposed the following hypothesis:

H2d. Warmth focused customers have more favorable attitudes toward brands applying matte packaging than they do toward those applying glossy packaging. However, competence focused customers have more favorable attitudes toward brands with glossy packaging than they do toward those applying matte packaging.

\section{Overview}

We conducted four studies to examine our hypotheses. In Study 1, we explored whether warmth and competence focused consumers prefer products contained in matte and glossy packages, respectively. In Study $2 \mathrm{a}$ and Study $2 \mathrm{~b}$, we replicated these effects in dynamic interactions. Finally, Study 3 extended the findings of the preceding three studies to determine the role of packaging finishes in brand impression formation and subsequent consumer behaviors. Additionally, the possible mechanism underlying these effects is explored.

\section{Study 1}

Study 1 aimed to examine whether warmth and competence focused consumers prefer products contained in matte and gloss packages, respectively. 


\section{Design, participants and procedure}

Materials. Krishna et al. (2017) proposed a layered-packaging taxonomy in which a packaging design could be physically categorized into outer, intermediate and inner packaging layers (for an example, see page 44 in Krishna et al., 2017). In the current study, four mobile phones (two grey color Redmi 2A and two white color Meizu M2 note) finished with matte and glossy inner packaging layers were used as the stimuli. Two mobile phones (one Redmi 2A and one Meizu M2 note) were finished in matte by spraying particles onto them, while the other two were finished in gloss by applying an acrylic coating onto the surfaces of the products. The matte-finished and gloss-finished stimuli were of a similar weight (product weight: matte-finished Redmi $2 \mathrm{~A}=142 \mathrm{~g}$, gloss-finished Remi $2 \mathrm{~A}=$ $141 \mathrm{~g}$, matte-finished Meizu M2 note $=158 \mathrm{~g}$, gloss-finished Meizu M2 note $=156 \mathrm{~g}$ ).

\section{Method}

In total, 42 undergraduates (22 women) were randomly recruited in exchange for complimentary candies. Participants were asked to review and rank the four mobile phones depending on their preference. Then, they completed the eightitem warmth and competence orientation scale (Cuddy et al., 2009). The questions were in the form of "in your friends' opinion, how [...] are you?" where the blank space would be filled with competent, confident, capable, skillful, friendly, warm, good-natured or sincere. Items were rated on sevenpoint scales $(1=$ not at all to $7=$ extremely). The ratings of friendliness, warmth, good-naturedness and sincerity were averaged to measure warmth orientation $(\alpha=0.82)$; while the ratings of competence, confidence, capability and skillfulness items were averaged to measure competence orientation $(\alpha=$ $0.83)$.

\section{Results and discussion}

Ordinal dummy codes were used to indicate participants' product preferences (1: the least to 4 : the most). The averaged preference for the two matte and glossy mobile phones was then calculated based on these codes. If the preference for matte phones was superior to the preference for glossy phones, a three was assigned; whereas if it was inferior, a one was assigned. If participants had an equal preference for matte and glossy phones, a two was assigned. A categorical regression (bootstrapping $=2,000$ ) with warmth and competence orientation as the predictors and product preference as the outcome was then conducted. Consistent with $\mathrm{H} 2 \mathrm{a}$, participants' warmth orientation positively predicted the preference for matte phones $(\beta=0.17, p<0.05)$, whereas their competence orientation did not. Similarly, participants' competence orientation positively predicted the preference for glossy phones $(\beta=0.58, p<0.001)$.

In the next studies, we moved the investigation into practical settings in everyday life. In addition, when investigating the warmth and competence focus, Study 1 regard a warmth and competence focus as an individual trait, that is, a tendency to rely more on warmth or competence information in attitude formation (Cuddy et al., 2009; Fiske, 2018). In Study 2a and $2 \mathrm{~b}$, we manipulated participants' warmth and competence focus in contexts. Collectively, we hypothesized that people are likely to select matte products while they interact with friends, lovers and family members (i.e. focus on social warmth). In contrast, people tend to select glossy products while they interact with supervisors, colleagues and subordinates in the workplace (i.e. focus on competence).

\section{Studies $\mathbf{2} \mathbf{a}$ and $\mathbf{2 b}$}

The second study comprised two experiments. Both tested the core hypothesis that product preference depends on an individual's warmth and competence focus. To engage people in social warmth and competence, Study $2 \mathrm{a}$ consisted of a social event in which participants selected a card to invite either close relatives to a celebration of grandma's birthday or employees to the company's annual meeting. Study $2 \mathrm{~b}$ involved a gift-giving task in which people wrapped gifts either for close friends or for workplace supervisors.

\section{Study 2 a}

Design, Participants and Procedure. This study was conducted in the cafeteria of a large semiconductor company in The Netherlands. The investigator randomly invited the employees to select invitation cards either for grandma's birthday party or the company's annual meeting. In total, 52 employees (29 women) participated in this study in exchange for a cup of coffee or tea. Two sets of invitation cards were designed. The first set comprised 10 cards in matte (grain) coating. The second set comprised 10 cards in a glossy coating (Appendix 1). The patterns on the cards in both sets were identical. For each participant, five matte and five glossy cards without duplicate patterns were randomly selected as the stimuli. The frequencies with which matte or glossy invitation cards were selected for close relatives or employees were then recorded as a measure of packaging preference.

Results and Discussion. A 2 (family vs business gathering) $\times 2$ (matte vs glossy card) chi-square test was conducted to test $H 2 a$. A significant difference was found in the selection of matte or glossy cards for family and business gatherings $\left(\chi^{2}(1)\right.$ $=27.20, p<0.001$ ), as listed in Table 1 . The findings showed that participants tended to select matte cards rather than glossy cards for activities concerning warmth and love; whereas, participants tended to select glossy cards rather than matte cards for activities where high competence was appreciated, which supported $H 2 a$.

\section{Study $2 b$}

Participants and Procedure. In total, 45 employees (22 women) in an international electronic company were invited to wrap a gift for a close friend or their boss. The experimenter was a member of this company, and so she knew their close friends and the boss of each participant well. Taking advantage of the end of year party preparations, the experimenter randomly asked those passing by to do her a favor and wrap a

Table 1 The frequency with which matte or glossy invitation cards were selected for a family versus business gathering

\begin{tabular}{lcc}
\hline Conditionlfinish & Matte card & Glossy card \\
\hline Family gathering & 89 & 41 \\
Business gathering & 47 & 83
\end{tabular}


gift for his (her) close friends or boss. With their agreement, the experimenter welcomed the participant to the room where was full of gifts for the end-of-year party. A box and four piles of wrappers (two matte and two glossy ones) were placed on the table. Participants were told that the gift for their close friend (boss) was already packaged in a box that they were required to wrap. The experimenter then received a phone call from an accomplice. After the call, the experimenter explained that she needed to leave for around $15 \mathrm{~min}$ and asked participants if they could select a paper from the four alternates and wrap the gift. Upon completion of gift-wrapping, participants were debriefed and asked not to discuss the study with anyone.

Material. As in Study 2a, two sets of matte and glossy wrappers were the stimuli. Each set had 10 different patterns. The first set comprised 10 wrappers in a matte (grain) coating. The second set comprised 10 wrappers in a glossy coating (Appendix 2). For each participant, two piles of matte wrappers and two piles of glossy wrappers without duplicate patterns were randomly selected as the stimuli. The four piles of matte and glossy wrappers were presented to the participant. Participants then chose wrappers for their close friend (boss) depending on their preferences. The frequencies with which matte or glossy wrappers were chosen for his (her) close friend (boss) were then recorded as a measure of packaging preference.

Results and Discussion. The results of the 2 (close friend versus boss) $\times 2$ (matte versus glossy wrapper) chi-square test showed a significant difference regarding whether matte or glossy papers were used to wrap gifts for their close friends and boss ( $\chi^{2}$ with Yates correction $=5.07, p<0.05$ ), as listed in Table 2 . The findings showed that participants consistently tended to select matte papers to wrap gifts for their close friends but glossy papers for wrapping gifts for their boss, which repeatedly supported $H 2 a$.

\section{Discussions of Studies $2 a$ and $2 b$}

Studies $2 \mathrm{a}$ and $2 \mathrm{~b}$ replicated the effects obtained in Study 1 by inducing participants' warmth and competence focus in close and business relationships, respectively. The findings indicated that participants preferred matte cards and wrappers when they considered their family and friends. By contrast, participants tended to select glossy cards and wrappers when they considered their bosses and superiors. Together, these results supported $\mathrm{H} 2 \mathrm{a}$. Two limitations, however, are that we did not demonstrate whether matte and glossy packaging affect brand impressions ( $\mathrm{H} 1 \mathrm{a}$ and $\mathrm{H} 1 \mathrm{~b}$ ) and how they work. These concerns were addressed in Study 3.

\section{Study 3}

The aim of Study 3 was to extend the findings of the preceding three studies to determine the role of packaging in forming sincere and competent brand impressions ( $\mathrm{H} 1 \mathrm{a}$

Table 2 The frequency with which matte or glossy papers were selected to wrap a gift for their close friend and boss

\begin{tabular}{lcc}
\hline Conditionlfinish & Matte wrapper & Glossy wrapper \\
\hline For the close friend & 16 & 6 \\
For the boss & 8 & 15 \\
\hline
\end{tabular}

and $H 1 b$ ). Additionally, as stated by $H 2 d$, we argue that consumers' focus on warmth and competence shifts the balance in terms of their concern with brand sincerity and competence, and thus the extent to which brands applying matte and glossy packaging is preferred, respectively. This hypothesis was based on two conditions. First, the different packaging finishes convey high brand sincerity and brand competence, as stated by $H 1 a$ and $H 1 b$. Second, because warmth focused (competence focused) consumers are more likely to value brand sincerity (competence) to form their brand attitudes, matte (glossy) packaging will help enhance brand attitudes through its conveyance of warmth (competence). To understand the mechanisms underlying the effects outlined by $H 1 a, H 1 b$ and $H 2 d$, we applied moderated mediation models.

\section{Methods}

We recruited a total of 128 Dutch mTrukers (65 women) with an average age of 33.58 years to participate in this study. Matte and glossy coffee packages of Tully's Coffee ${ }^{\circledR}$ adopted from the study by Magnier et al. (2016) were the stimuli.

We evaluated the extent to which the participants perceived a brand as warm, friendly and honest (brand sincerity: $\alpha=0.88$ ), as well as competent, capable and successful (brand competence: $\alpha=0.89$; Aaker, 1997; Aaker et al., 2012). Next, using an eight-item warmth and competence questionnaire ( $\alpha=0.87$ and 0.82; Cuddy et al., 2009), we asked the participants to evaluate the brand Tully's Coffee ${ }^{\circledR}$ by rating the following two items: "I like this brand" and "I would recommend Tully's Coffee ${ }^{\circledR}$ if you need buying a pack of coffee" $(\alpha=0.84)$. They also evaluated Tully's Coffee ${ }^{\circledR}$ product by the following two items: "the coffee appeals to me" and "from my perspective, the coffee is very wieldy" ( $\alpha=0.83)$. Furthermore, purchase intention was evaluated using the following items: "I intend to purchase this coffee immediately" and "I will purchase this coffee if I need one" $(\alpha=0.86)$. Participants rated the items on a seven-point scale with anchors ranging from 1 (not at all) to 7 (extremely). Demographics and brand familiarity were also measured.

\section{Results}

Brand familiarity. Before performing the analyzes, we verified whether the participants were familiar with the brand Tully's Coffee $^{\circledR}$. Seven participants who provided ratings higher than three on brand familiarity (seven-point scale) were excluded from the analyzes; therefore, prior knowledge of the brand did not influence the outcome variables.

Brand sincerity and competence. We identified the significant main effects of packaging. Specifically, brands applying matte packaging were perceived as more sincere than those applying glossy packaging $(M=5.01$ vs $3.68, F(1,120)=69.40, p<$ 0.001 ); therefore, $\mathrm{H} 1 \mathrm{a}$ was supported. Brands applying glossy packaging were perceived as more competent than those applying matte packaging $(M=4.60$ vs $3.55, F(1,120)=$ $29.11, p<0.001)$; hence, $H 1 b$ was supported.

Brand attitudes. Spotlight analyzes (Spiller et al., 2013) revealed that high warmth focused participants (1 standard deviation above the mean for warmth scores) favored brands applying matte packaging over those applying glossy packaging 
$(\beta=0.51, p<0.001)$. The resulting pattern was reversed when participants had low warmth scores (1 standard deviation below the mean for warmth scores; $\beta=-0.27, p<0.05)$. By contrast, high competence focused participants (1 standard deviation above the mean for competence scores) favored brands applying glossy packaging over those applying matte packaging $(\beta=-0.26, p<0.05)$. Low competence focused participants (1 standard deviation below the mean for competence scores) had similar brand attitudes toward glossy and matte packaging. According to these results, H2d was supported.

Product attitudes and purchase intentions. Spotlight analyzes indicated that high warmth focused participants favored matte-packaged products over glossy packaged products $(\beta=0.53, p<0.001)$. A reverse pattern was found when participants had low warmth scores $(\beta=-0.26, p<$ 0.05). As expected, high competence focused participants favored glossy packaged products over matte-packaged products $(\beta=-0.26, p<0.05)$. No significant result was found among low competence focused participants. According to these results, $H 2 b$ was supported.

Additional spotlight analyzes revealed that high warmth focused participants were more willing to purchase mattepackaged products than they did glossy packaged products $(\beta=0.25, p<0.05)$; whereas, low warmth focused participants were more willing to purchase glossy packaged products than matte-packaged ones $(\beta=-0.58, p<0.001)$. As expected, high competence focused participants were more willing to buy glossy packaged products than they did mattepackaged products $(\beta=-0.26, p<0.05)$. Low competence focused participants had similar willing purchase intentions toward glossy and matte-packaged products. According to these results, $H 2 c$ was supported.

Moderated mediation analyzes. To explore whether matte and glossy packaging would enhance brand attitudes through brand sincerity and competence and whether these potential mediating paths would be moderated by participants' warmth and competence focus, we conducted mediation and moderated mediation analyzes (Hayes and Little, 2017). Considering our hypotheses, we coded matte packaging as 1 and glossy packaging as -1 .

The mediation model (Model 4 with 5,000 bootstrap samples; Hayes and Little, 2017) indicated that matte packaging enhanced brand attitudes through brand sincerity (indirect effect of packaging-brand sincerity-brand attitudes: $E S=0.44,95 \%$ confidence interval $(C I)=0.30$ to 0.60$)$. The moderated mediation model (Model 14 with 5,000 bootstrap samples; Hayes and Little, 2017) revealed that participants' warmth focus significantly enhanced the positive influence of brand sincerity on favorable brand attitudes ( $E S=0.44,95 \%$ $\mathrm{CI}=0.30$ and 0.60 ). Parallelly, glossy packaging enhanced brand attitudes through brand competence (Model 4 with 5,000 bootstrap samples; Hayes and Little, 2017; indirect effect of packaging-brand competence-brand attitudes: $E S=$ $0.26,95 \% \mathrm{CI}=0.14$ and 0.42$)$; and, participants' competence focus significantly enhanced the positive influence of brand competence on favorable brand attitudes (Model 14 with 5,000 bootstrap samples; Hayes and Little, 2017; ES $=0.44,95 \%$ $\mathrm{CI}=0.30$ and 0.60$)$.

\section{Discussion}

Study 3 extended the findings of the preceding three studies to brand and product management. In particular, Study 3 revealed moderated mediation effects; it not only provided considerable insight into whether certain packaging finishes affect consumer evaluations but also indicated the mechanisms underlying the effects. First, the study demonstrated that matte and glossy packaging may activate the knowledge constructs of warmth and competence and spill over to brand impressions. The coffee brand that packaged its products in a matte bag was perceived to be a sincere brand, but the coffee brand that packaged its products in a glossy bag was perceived to be a competent brand; these findings can, thus, serve as a reference for brand managers in shaping desired brand impressions. Second, we observe that although both sincerity and competence are desired characteristics when people consider a brand, people value brands that match their warmth or competence focus. In addition, warmth focused (competence focused) participants had better attitudes and higher purchase intentions toward matte-packaged (glossy packaged) products. Finally, the mediation models showed that matte (glossy) packaging engendered favorable brand attitudes through high brand sincerity (competence). Participants' warmth and competence focus even enhanced the positive influences of brand sincerity (competence) on favorable brand attitudes.

Collectively, these findings are consistent with the idea that managers could consider using matte and glossy packaging finishes as a vehicle for conferring favorable impressions of sincerity and competence upon brands and attracting specific target consumers (i.e. warmth focused and competence focused consumers). Furthermore, consumers would value matte-packaged (glossy packaged) products that match their warmth (competence) focus.

\section{General discussion}

This study is the first to systematically investigate the effects of packaging finishes on brand impressions and subsequent consumer behaviors (i.e. brand attitudes, product preferences and attitudes and purchase intentions). We conducted four studies. In summary (below list);

Summaries of the results found in the present research:

1 H1a. matte packaging-brand sincerity (all); supported by Study 3 (coffee packs).

$2 \quad H 1 b$. glossy packaging-brand competence (all); supported by Study 3 (coffee packs).

3 H2a. product preference; supported by Study 1 (mobile phones), Study $2 a$ (invitation cards) and Study $2 b$ (wrappers):

- matte packaging > glossy packaging (warmth focused), and

- glossy packaging > matte packaging (competence focused).

$4 \quad H 2 b$. product attitudes; supported by Study 3 (coffee packs):

- matte packaging > glossy packaging (warmth focused), and

- glossy packaging > matte packaging (competence focused).

5 H2c. purchase intentions; supported by Study 3 (coffee packs): 
- matte packaging > glossy packaging (warmth focused), and

- glossy packaging > matte packaging (competence focused).

6 H2d. brand attitudes; supported by Study 3 (coffee packs):

- matte packaging > glossy packaging (warmth focused), and

- glossy packaging > matte packaging (competence focused).

7 Moderated mediation effects; supported by Study 3 (coffee packs),

- matte packaging-brand sincerity-brand attitudes, product attitudes and purchase intentions (warmth focused),

- glossy packaging-brand competence-brand attitudes, product attitudes, and purchase intentions (competence focused).

Note: all = all participants; warmth focused = warmth focused participants; competence focused $=$ competence focused participants.

The first three studies explored whether warmth and competence focused consumers preferred matte and glossy packaging finishes, respectively. In Study 1, we measured participants' warmth and competence orientations and examined the effects of such orientations on their preference for matte- and glossy finished mobile phones. Using a grandmother's birthday party and annual review meeting as the contexts, we replicated these effects in Study 2 a by revealing that people tended to choose matte invitation cards for inviting their close relatives to celebrate their grandmother's birthday because of their focus on social intimacy; however, people tended to select glossy invitation cards for inviting employees to attend a company's annual meeting because of their focus on work competence. Similarly, Study $2 \mathrm{~b}$ indicated that participants tended to choose matte and glossy papers to wrap gifts for their friends and bosses, respectively. The findings of these three studies were determined to robustly support $H 2 a$.

To extend the findings of the three preceding studies to the context of brand and product management, we conducted Study 3, which revealed that warmth focused (competence focused) participants positively responded to matte (glossy) packaged products and the associated brand. With the increasing bodies of evidence regarding the effects of packaging design, understanding the mechanisms underlying such effects is imperative. Using moderated mediation models and on the basis of the aforementioned results, we included brand sincerity and competence as mediators in Study 3 to explain the mechanisms. We determined that participants' warmth focus enhanced the positive influence of brand sincerity on favorable evaluations (i.e. brand attitudes, product attitudes and purchase intentions), respectively. We observed similar relationships that participants' competence focus promoted the positive influence of brand competence on favorable evaluations. Overall, we suggest that matte and glossy packaging be used as a vehicle for shaping sincere and competent impressions of brands and attracting specific target consumers (i.e. warmth focused and competence focused consumers).

\section{Theoretical and managerial implications}

This study has several contributions. First, for the literature on packaging design, we determined the influence of different packaging finishes on product attractiveness. Furthermore, the first three studies (Studies 1, 2a and 2b) initially revealed that although product attractiveness would depend on matte and glossy packaging, the perception of product attractiveness would also depend on whether consumers focus on social warmth or competence. Notably, we could also observe similar design practices. For example, country-style fashion emphasizing relaxation, warmth and comfort tends to have a matte finish, and modern-style fashion focusing on efficiency and professionalism tends to have a glossy finish.

In addition, when investigating the warmth and competence focus, there are two approaches to consider. One option is to take the warmth and competence focus as an individual trait, that is, as a tendency to rely more on corresponding information in attitude formation. An alternate is to induce certain focuses in contexts. Studies $2 \mathrm{a}$ and $2 \mathrm{~b}$ showed that when people interact with friends, lovers and family members, they would focus on social warmth. In contrast, when people interact with supervisors, colleagues and subordinates in the workplace, they would shift their focus on competence. The account of focus activation leads to two applications. First, customers at home and in the workplace may tend to be warmth and competence focused, respectively. Second, marketing efforts such as advertisement appeals craft and ambiance arrangements could aid in consumers' warmth and competence focus.

Similar to how the brand personality concept assists firms in brand positioning and differentiation, our findings (Study 3) suggest that companies use matte and glossy packaging finishes conveying brand sincerity and competence. Research demonstrated that warmth (sincerity) and competence impressions could increase purchase intentions and brand loyalty (Kervyn et al., 2012). Consequently, brands and firms attempt to explicitly tailor these impressions. For example, firms participate in charity donations or community support to increase consumers' perceptions of brand sincerity, and other firms invest in independent consumer reports or credibility endorsements to enhance consumers' perceptions of competence (Aaker et al., 2010; Heide et al., 2008; Hess and Melnyk, 2016). However, a growing body of literature indicates that consumers are cautious about these commercial effects and may resist attempts at persuasion (Odoue and de Pechpeyrou, 2011). In particular, impressions of sincerity are difficult to cultivate because they are often interpreted as a firm "trying to get something" (Reeder et al., 2002). Hence, we suggest that firms use matte and glossy packaging as an alternate method to associate a brand with warmth and competence, respectively.

Conceptually, this work also extends the growing body of literature on the stereotype content model (warmth and competence dimensions; Fiske et al., 2002) in terms of brand management and consumer behaviors (Aaker et al., 2010; Wang et al., 2017). Relevant research showed that placing “. org" at the end of a domain name (the top-level domain for nonprofit organizations) could confer perceptions of warmth upon a brand, but placing ".com" at the end of a domain name (the top-level domain for profit-oriented organizations) could 
confer perceptions of competence upon a brand (Aaker et al., 2010). Wang et al. (2017) demonstrated that a broad smile tends to be perceived as warmer but less competent than a slight smile. In a crowdfunding context, funders with broad smiles are more likely to receive social support and small-scale donations, whereas those with slight smiles are more likely to receive large investments. Our study complements these findings and proposes that matte (glossy) packaging finishes convey warmth (competence), which helps establish impressions of a brand as sincere (competent) and then attracts warmth focused (competence focused) consumers. A novel finding provided by the current study is the complex and dynamic nature of consumers' warmth and competence focus on packaging finish, brand impressions and subsequent consumer behaviors. As mentioned, using moderated mediation models in Study 3, we found that matte packaging attracts warmth focused consumers through conveying brand sincerity (warmth related impressions of a brand) and that glossy packaging attracts competence focused consumers through conveying brand competence (professionalism related impressions upon a brand).

\section{Limitations and future research directions}

Although the current study offers valuable implications for researchers and practitioners, it also has limitations that merit attention. First, to ensure our analyzes were sufficiently precise, we manipulated matte and glossy packaging finishes but maintained the other design features. However, the literature suggests that perceivers can use colors (e.g. blue and pink) as masculine and feminine gender cues to indicate a brand's competence and warmth, respectively (Hess and Melnyk, 2016). We suggest that future studies examine the effects of the interactions of a matte and glossy finish with other product features such as colors (cool vs warm tones). Similarly, we examined only one product: coffee. We could not exclude the fact that packaging design is more critical for certain types of products (e.g. packaging of jewelry may be more critical in the purchase decision than a shoebox) or that differences occur as a consequence of products' intrinsic attributes (e.g. plush toys are intrinsically warm, but power tools are intrinsically competent). Thus, product types may moderate the findings we observed and should be explored in the future.

From a conceptual perspective, although warmth and competence information is central to impression formation and management, people process both forms of information asymmetrically. People rely more on warmth than competence information in shaping impressions (Fiske et al., 2007; Fiske et al., 2002). We observed similar results in Study 3, in which matte packaging finishes exerted stronger effects on participants' evaluations and purchase intentions than did glossy packaging finishes. Another interesting exploration involves cultural differences. In individualistic contexts, a sense of professionalism and competence increases the attractiveness of the evaluated targets. In collectivist contexts, however, increased competence might foster a sense of estrangement and, in turn, reduce the evaluated targets' attractiveness. Therefore, a topic for future research is to examine the extent to which, if at all, different products and distinct cultures moderate our findings.

In summary, this study explored whether managers could use packaging finishes as a vehicle for establishing desired brand impressions and the mechanisms underlying this process. Although our findings might raise a new set of questions, we believe that meaningful answers have been provided, benefiting both packaging design practices and research.

\section{References}

Aaker, J.L. (1997), "Dimensions of brand personality", fournal of Marketing Research, Vol. 34 No. 3, pp. 347-356.

Aaker, J.L., Garbinsky, E.N. and Vohs, K.D. (2012), "Cultivating admiration in brands: warmth, competence, and landing in the golden quadrant", fournal of Consumer Psychology, Vol. 22 No. 2, pp. 191-194.

Aaker, J., Vohs, K.D. and Mogilner, C. (2010), "Nonprofits are seen as warm and for-profits as competent: firm stereotypes matter", fournal of Consumer Research, Vol. 37 No. 2, pp. 224-237.

Briand Decré, G. and Cloonan, C. (2019), "A touch of gloss: haptic perception of packaging and consumers' reactions", fournal of Product \& Brand Management, Vol. 28, pp. 117-132.

Celhay, F. and Trinquecoste, J.F. (2015), "Package graphic design: investigating the variables that moderate consumer response to atypical designs", Fournal of Product Innovation Management, Vol. 32 No. 6, pp. 1014-1032.

Cornil, Y., Chandon, P. and Krishna, A. (2017), "Does red bull give wings to vodka? Placebo effects of marketing labels on perceived intoxication and risky attitudes and behaviors", Fournal of Consumer Psychology, Vol. 27 No. 4, pp. 456-465.

Cuddy, A.J.C., Fiske, S.T., Kwan, V.S.Y., Glick, P., Demoulin, S., Leyens, J.-P., Bond, M.H., Croizet, J.-C., Ellemers, N., Sleebos, E., Htun, T.T., Kim, H.-J., Maio, G., Perry, J., Petkova, K., Todorov, V., Rodríguez-Bailón, R., Morales, E., Moya, M., Palacios, M., Smith, V., Perez, R., Vala, J. and Ziegler, R. (2009), "Stereotype content model across cultures: towards universal similarities and some differences", British Fournal of Social Psychology, Vol. 48 No. 1, pp. 1-33.

Deng, X. and Srinivasan, R. (2013), "When do transparent packages increase (or decrease) food consumption?", fournal of Marketing, Vol. 77 No. 4, pp. 104-117.

Fenko, A., Lotterman, H. and Galetzka, M. (2016), "What's in a name? The effects of sound symbolism and package shape on consumer responses to food products", Food Quality and Preference, Vol. 51, pp. 100-108.

Fiske, S.T. (2018), "Stereotype content: warmth and competence endure", Current Directions in Psychological Science, Vol. 27 No. 2, pp. 67-73.

Fiske, S.T., Cuddy, A.J.C. and Glick, P. (2007), "Universal dimensions of social cognition: warmth and competence", Trends in Cognitive Sciences, Vol. 11 No. 2, pp. 77-83.

Fiske, S.T., Cuddy, A.J.C., Glick, P. and Xu, J. (2002), “A model of (often mixed) stereotype content: competence and warmth respectively follow from perceived status and competition", Fournal of Personality and Social Psychology, Vol. 82 No. 6, pp. 878-902. 
Fleming, R.W., Torralba, A. and Adelson, E.H. (2004), "Specular reflections and the perception of shape", fournal of Vision, Vol. 4 No. 9, pp. 798-820.

Fujisaki, W., Tokita, M. and Kariya, K. (2015), "Perception of the material properties of wood based on vision, audition, and touch", Vision Research, Vol. 109, pp. 185-200.

Harlow, H.F. (1958), "The nature of love", American Psychologist, Vol. 13 No. 12, pp. 673-685.

Hayes, A.F. and Little, T.D. (2017), Introduction to Mediation, Moderation, and Conditional Process Analysis: A RegressionBased Approach, The Guilford Press, New York, NY.

Heide, M., Vaaland, T.I. and Grønhaug, K. (2008), "Corporate social responsibility: investigating theory and research in the marketing context", European fournal of Marketing, Vol. 42 Nos 9/10, pp. 927-953.

Hess, A.C. and Melnyk, V. (2016), "Pink or blue? The impact of gender cues on brand perceptions", European fournal of Marketing, Vol. 50 Nos 9/10, pp. 1550-1574.

Kergoat, M., Giboreau, A., Nicod, H., Faye, P., Diaz, E., Beetschen, M.-A. and Meyer, T. (2012), "Consumer preference for tactile softness: a question of affect intensity?", fournal of Sensory Studies, Vol. 27 No. 4, pp. 232-246.

Kervyn, N., Fiske, S.T. and Malone, C. (2012), "Brands as intentional agents framework: how perceived intentions and ability can map brand perception", fournal of Consumer Psychology, Vol. 22 No. 2, pp. 166-176.

Kim, J., Marlow, P.J. and Anderson, B.L. (2012), "The dark side of gloss", Nature Neuroscience, Vol. 15 No. 11, pp. 1590-1595.

Krishna, A., Cian, L. and Aydınoğlu, N.Z. (2017), "Sensory aspects of package design", fournal of Retailing, Vol. 93 No. 1, pp. 43-54.

Magnier, L. and Schoormans, J. (2017), "How do packaging material, colour and environmental claim influence package, brand and product evaluations?", Packaging Technology and Science, Vol. 30 No. 11, pp. 735-751.

Magnier, L., Schoormans, J. and Mugge, R. (2016), "Judging a product by its cover: packaging sustainability and perceptions of quality in food products", Food Quality and Preference, Vol. 53, pp. 132-142.

Marckhgott, E. and Kamleitner, B. (2019), "Matte matters: when matte packaging increases perceptions of food naturalness", Marketing Letters, Vol. 30 No. 2, pp. 1-12.

Marlow, P.J. and Anderson, B.L. (2013), "Generative constraints on image cues for perceived gloss", fournal of Vision, Vol. 13 No. 14, pp. 1-23.

Nayar, S.K. and Oren, M. (1995), "Visual appearance of matte surfaces”, Science, Vol. 267 No. 5201, pp. 1153-1156.

Odoue, P. and de Pechpeyrou, P. (2011), "Consumer cynicism: from resistance to anti-consumption in a disenchanted world?", European fournal of Marketing, Vol. 45 Nos 11/12, pp. 1799-1808.

Orth, U.R. and Malkewitz, K. (2008), "Holistic package design and consumer brand impressions", fournal of Marketing, Vol. 72 No. 3, pp. 64-81.

Peck, J. and Wiggins, J. (2006), "It just feels good: consumers' affective response to touch and its influence on persuasion", Fournal of Marketing, Vol. 70 No. 4, pp. 56-69.
Piqueras-Fiszman, B. and Spence, C. (2012), "The influence of the feel of product packaging on the perception of the oralsomatosensory texture of food", Food Quality and Preference, Vol. 26 No. 1, pp. 67-73.

Qi, L., Chantler, M.J., Siebert, J.P. and Dong, J. (2012), "How mesoscale and microscale roughness affect perceived gloss", Proceedings of the 3rd International Conference on Appearance, pp. 48-51.

Reeder, G.D., Kumar, S., Hesson-McInnis, M.S. and Trafimow, D. (2002), "Inferences about the morality of an aggressor: the role of perceived motive", fournal of Personality and Social Psychology, Vol. 83 No. 4, pp. 789-803.

Silvia, P.J., Christensen, A.P., Cotter, K.N., Jackson, T.A., Galyean, C.B., McCroskey, T.J. and Rasheed, A.Z. (2018), "Examining aesthetic preferences for shiny objects", Empirical Studies of the Arts, Vol. 36 No. 1, pp. 101-113.

Spiller, S.A., Fitzsimons, G.J., Lynch, J.G. and McClelland, G.H. (2013), "Spotlights, floodlights, and the magic number zero: simple effects tests in moderated regression", Fournal of Marketing Research, Vol. 50 No. 2, pp. 277-288.

Sumioka, H., Nakae, A., Kanai, R. and Ishiguro, H. (2013), "Huggable communication medium decreases cortisol levels", Scientific Reports, Vol. 3 No. 1, p. 6.

Tai, K., Zheng, X. and Narayanan, J. (2011), "Touching a teddy bear mitigates negative effects of social exclusion to increase prosocial behaviors", Social Psychological and Personality Science, Vol. 2 No. 6, pp. 618-626.

Tiest, W.M.B. and Kappers, A.M.L. (2007), "Haptic and visual perception of roughness", Acta Psychologica, Vol. 124 No. 2, pp. 177-189.

Wang, Z., Mao, H., Li, Y.J. and Liu, F. (2017), "Smile big or not? Effects of smile intensity on perceptions of warmth and competence", fournal of Consumer Research, Vol. 43, pp. 787-805.

Yanagisawa, H. and Yuki, N. (2011), "Deviations of visual expectation from somatosensory experience in emotional quality: effects of surface characteristic in context of ifting object", Proceedings of the ASME 2011 International Design Engineering Technical Conferences \& Computers and Information in Engineering Conference, pp. 825-832.

Ye, N., Morrin, M. and Kampfer, K. (2019), "From glossy to greasy: the impact of learned associations on perceptions of food healthfulness", Fournal of Consumer Psychology, Vol. 30 No. 1, pp. 94-124.

\section{Further reading}

Kniazeva, M. and Belk, R.W. (2007), "Packaging as vehicle for mythologizing the brand", Consumption Markets \& Culture, Vol. 10 No. 1, pp. 51-69.

Van Rompay, T., Pruyn, A. and Tieke, P. (2009), "Symbolic meaning integration in design and its influence on product and brand evaluation", International fournal of Design, Vol. 3 No. 2, pp. 19-26.

\section{Corresponding author}

Yu-Shan Athena Chen can be contacted at: y.s.chen@tue.nl 
Appendix 1. Snapshots of the matte and glossy invitation cards used in Study 2a

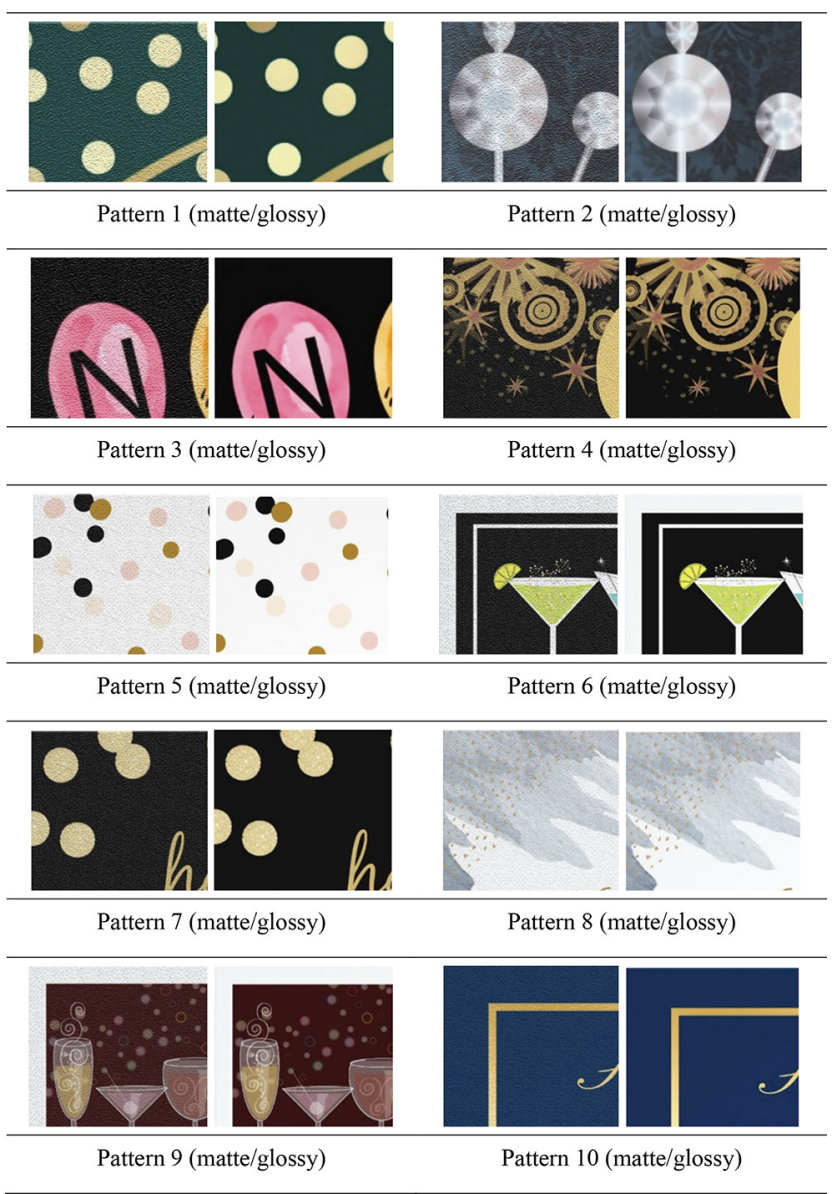


Appendix 2. Snapshots of the matte and glossy wrappers used in Study $\mathbf{2 b}$

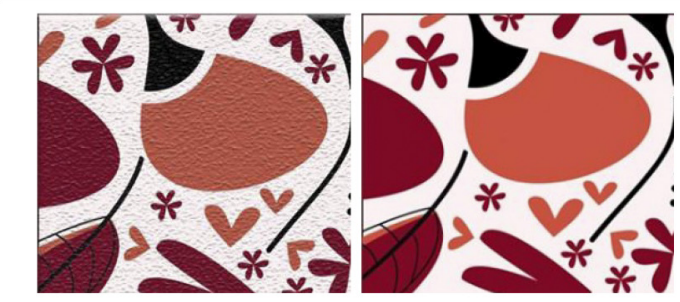

Pattern 1 (matte/glossy)

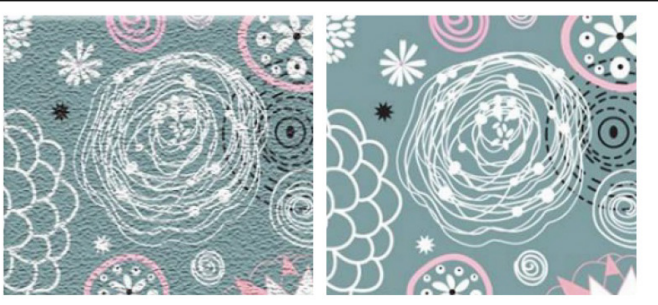

Pattern 2 (matte/glossy)

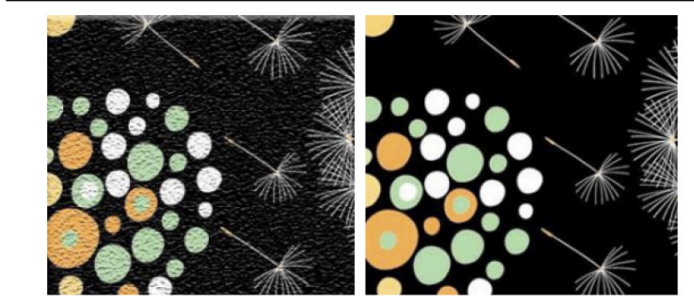

Pattern 3 (matte/glossy)

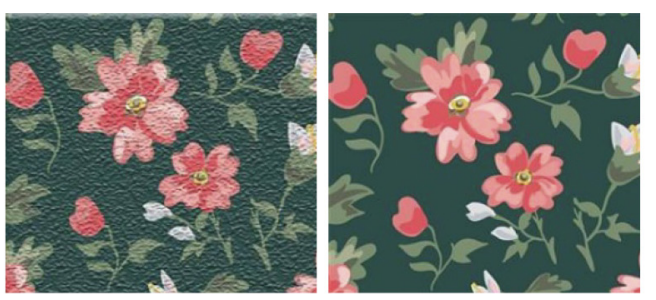

Pattern 4 (matte/glossy)
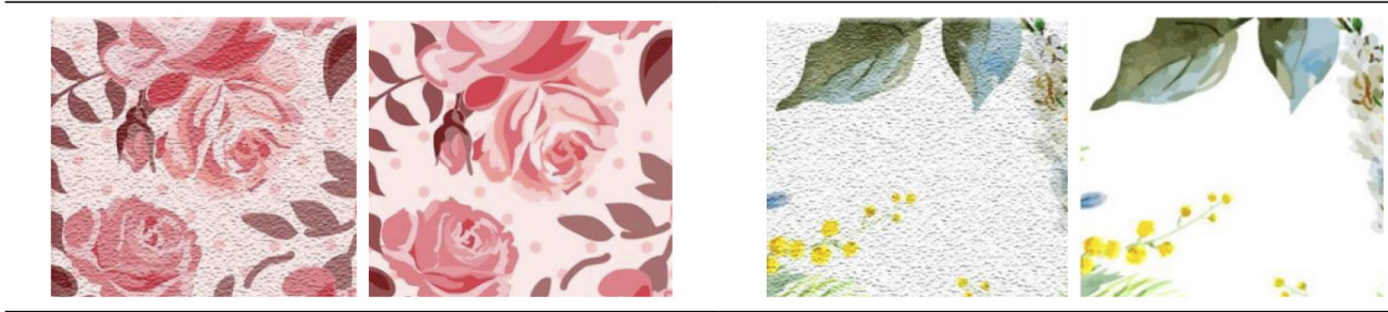

Pattern 5 (matte/glossy)

Pattern 6 (matte/glossy)

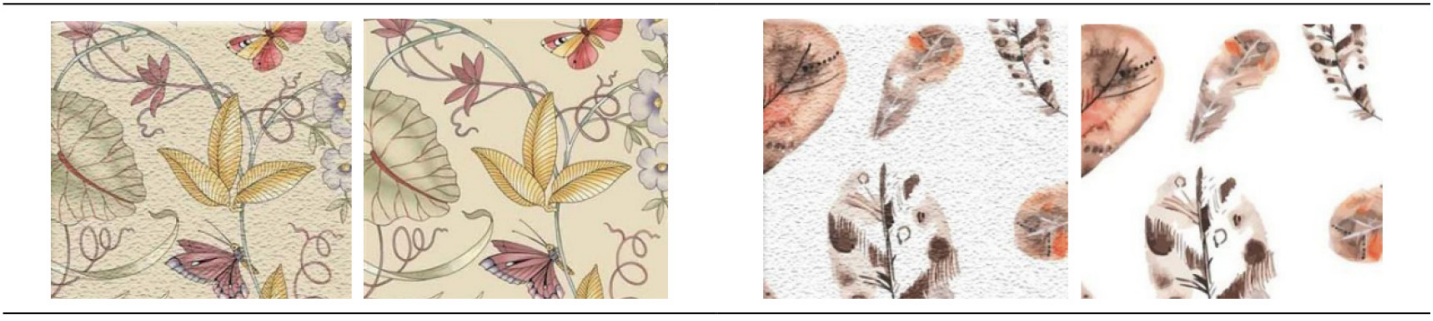

Pattern 7 (matte/glossy)

Pattern 8 (matte/glossy)

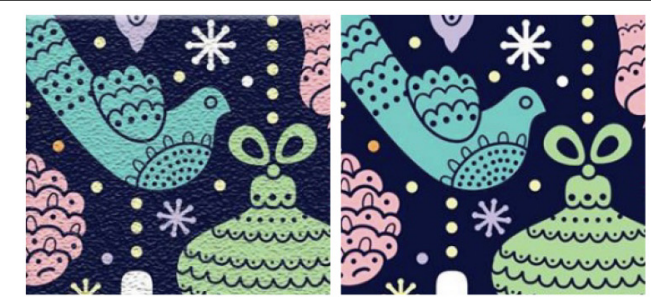

Pattern 9 (matte/glossy)
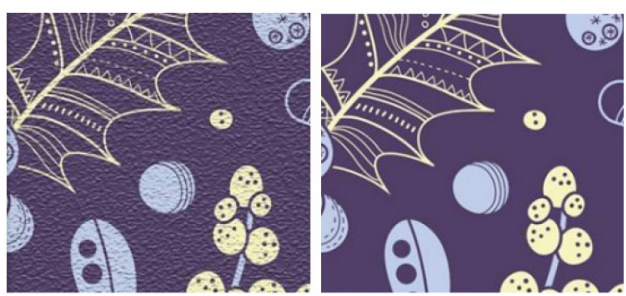

Pattern 10 (matte/glossy) 